This animal deserves a far greater measure of scientific investigation than it now receives, especially in view of the already great, and still growing, value of the poultry industry. The memorandum recommends that efforts be made to attract young workers into this field of research to investigate such problems as the endocrine control of the secretory activity of the oviduct, the role of hormones in the moult and broodiness in hens and the action of hormones on the differentiation of sex and on gonadal development. The Poultry Research Centre has facilities for intensifying its research programme along these lines if the scientists become available to conduct the work.

There would appear to be a close connexion between endocrinology and genetics; but there are, in fact, only a few examples in support of this contention. The relation between these two subjects was discussed at a meeting to which eminent geneticists were invited. Much closer co-operation than had previously existed between workers in these two sciences was thought desirable for their mutual benefit in the resolution of many complex problems.

No direct approach has been made to the problem of infertility due to physiological causes in farm animals, except in so far as it may arise from the ingestion of cestrogenic substances in pasture plants. Such a substance has been isolated from red clover and some British grasses in concentrations equivalent to 2-6 $\mu \mathrm{gm}$. of the naturally occurring cestrogen per gram of the dried plant. It would not seem to be directly responsible for the rise in percentage of non-fatty solids of the milk of cows put out to graze after prolonged periods of stall feeding; but it is considered feasible that the intermittent occurrence of short periods of herd-infertility which has been reported in cattle might be attributed to sudden changes in the amounts of cstrogen ingested. If this be the case, failure to reproduce would most likely result from the inability of the blastocyst to become implanted because of the disturbance to the cestrogen-progesterone equilibrium.

The reviews which have been discussed by the Committee by no means exhaust the topics that could be presented on endocrinological problems in agriculture. Nevertheless, they give a broad glimpse of the many pathways along which future research could benefit the farming industry. Already, the first steps have been taken along several of these paths.

\title{
A CODE FOR PROTECTION AGAINST RADIATION
}

$\mathrm{F}^{\mathrm{o}}$ OR the first time a comprehensive manual on the protection of radiological workers has been issued by the Office of the Prime Minister and First Lord of the Treasury (Atomic Energy), Ministry of Health, Department of Health for Scotland and Ministry of Health and Local Government for Northern Ireland*. This does not imply, however, that radiation protection has hitherto been neglected, either in hospitals or by other responsible authorities in Britain. So long ago as 1921 the British X-ray and Radium Protection Committee was formed, largely as a result of the pioneering work of Prof. Sydney Russ, "with the object of arresting the sequence of casualties to X-ray and radium workers". Many of the recommendations of the British Committee were adopted by the International Commission on Radiological Protection in 1928, and the Committee continued in being until 1948, when it published the seventh and last revision of its report. For more than a quarter of a century the recommendations of the British Committee formed the basis of radiological protection in Britain. These recommendations have been supplemented over the past ten years by an "Introductory Manual on the Control of Health Hazards from Radioactive Materials", prepared for the Medical Research Council by the Ministry of Supply, Atomic Energy Research Eistablishment.

The new "Code of Practice for the Protection of Persons exposed to Ionizing Radiations" is designed to meet the needs of an age in which the production, variety and uses of radioactive materials have enormously increased. This informative and extremely useful manual has been prepared by a distinguished committee, with Sir Charles Darwin as chairman, which was set up under the Radioactive Substances Act to advise Ministers on questions of radiation

* Code of Practice for the Protection of Persons exposed to Ionizing * Code of Practice for the Protection of Persons exposed to Ionizing
8s. net. protection. The Code is based on the scientific findings of other bodies, notably on the recommendations of the International Commission on Radiological Protection (1955) and on the Medical Research Council's report on "The Hazards to Man of Nuclear and Allied Radiations" (1956).

The general rules of the Code make it clear that the officer in charge of a department in which ionizing radiations are used is responsible for the radiological safety of the staff. It is advised further that one member of such a department should be designated as safety officer, to be responsible for the necessary protection measures. The word 'must' is used to indicate essential requirements and the word 'should' reserved for desirable but presumably not always necessary or practicable requirements. Every employee must, in future, sign a statement that he has read and understood those sections of the Code applying to the circumstances of his work.

The Code of Practice is presented in two parts : Part $A$ deals with the use of X-rays for diagnostic purposes and the use of X-rays and $\gamma$-ray beam units for therapeutic purposes; Part $B$ concerns the medical uses of radioactive isotopes, sealed or unsealed. In both parts rules of protection are laid down without detailed specifications about installations or techniques, but no important points are overlooked. Part $A$, for example, contains all the minimal requirements for $\mathrm{X}$-ray tube housings, diaphragms, fluorescent screens, observation windows, protective clothing, etc., and Part $B$ gives most valuable information on the types of laboratory required for different levels of activity of radioisotopes of various defined grades of toxicity. Practical details are also given relating instrument response to levels of contamination and describing sensible procedures to be followed if radioactive materials are spilt. No rules are yet given on the 
disposal of radioactive waste; this problem, which impinges on some of the responsibilities of local authorities, is still under consideration.

One half of the eighty-odd pages of the manual is given to a well-planned supplement which admirably summarizes the essential findings of the International Commission on Radiological Protection (1955) and gives the technical information necessary for implementation of the rules of Parts $A$ and $B$. This section also includes a glossary defining all the technical terms appearing in the manual.

Comparison of the new Code with the older recommendations illustrates the increasingly cautious attitude now taken towards any irradiation of human beings additional to that received from natural sources. The earliest recommendation of a 'tolerance dose' of $1 \mathrm{r}$. per week has been gradually abandoned in favour of a 'maximum permissible dose' of $0 \cdot 3 \mathrm{r}$. per week, now accompanied by still stricter provisions in terms of maximum cumulative doses for whole-body exposure. The limits applicable for exposure up to thirty years of age and per decade thereafter are equivalent to an average weekly dose of $0.1 \mathrm{r}$. "This is one-third of the maximum permissible weekly dose. In the case of long-term exposure, the protection must be planned accordingly" (Code, p. 52).

On the other hand, less emphasis than formerly is placed upon the necessity for regular blood counts. Provided adequate radiation monitoring is carried out in all circumstances involving occupational exposure, routine blood counts are suggested only in the case of workers who receive average doses exceeding one-half the maximum permissible weekly level averaged over a period of three months, and in the event of a worker acquiring a significant amount of an isotope deposited internally. Presumably the Committee considered that doses of radiation insufficient to affect the blood count could be harmful and that a blood count therefore afforded insufficient security at the lower dose-levels. Even so, the blood count does offer a biological test which cannot be circumvented accidentally or intentionally by anyone, and which can give an indication of high doses which for a number of reasons could be missed by purely physical monitoring.

Hours of work receive no mention in the Code, although the British X-ray and Radium Protection Committee was forthright on this point, recommending a five-day week, "the off-days to be spent as much as possible out-of-doors and not less than four weeks holiday a year, preferably consecutively". No reason is given for this omission in the present Code. It is convenient administratively and it is probably correct to formulate regulations for radiation safety apart from rules about working hours but, in my opinion, it would be unwise to separate these considerations in the case of hospital radiological staff who, in their daily contact with the sick, are exposed to the risk of infection as well as to an agent noted for its toxicity to the blood-forming tissues.

A very great service, however, has been performed by Sir Charles Darwin and his colleagues in producing so useful and valuable a document, which has a field of application much wider than hospital radiological work. The manual must be in the hands of all those who use ionizing radiations in the National Health Service; it should-and almost certainly will-be beside all others who use ionizing radiations for any purpose whatever.

The Minister of Labour and National Service has recently issued a preliminary draft of a new Code of Regulations to safeguard workers employed in industry against the effect of ionizing radiations (Factories (Ionizing Radiations) special Regulations : Preliminary Draft. Pp. 16. H.M. Stationery Office. $9 d$. net). The regulations deal with industrial X-rays and sealed radioactive sources. Draft regulations to deal with unsealed or open sources are in the course of preparation.
F. W. SpIERs

\section{OBITUARIES}

The Right Hon. Viscount Cherwell, P.C., C.H., F.R.S.

Frederick Alexander Lindemane, Viscount Cherwell, was born in Baden-Baden on April 5, 1886, and died in Oxford on July 3, 1957. His father, a naturalized Briton who came from an Alsatian family of French loyalty, was a wealthy engineer; his mother was English. He shared with his father an interest in astronomy and in instrument-making; and physics and mathematics became his principal subjects when he studied at the University of Berlin under Rubens, Planck and Nernst.

His Ph.D. dissertation was completed in 1910 ; it was on the atomic heats of metals at low temperatures, and with Nernst he published some important papers on this subject. Altogether he produced nearly twenty papers before 1915 ; besides the atomic heat work they dealt with subjects as varied as a glass transparent to X-rays ('Lindemann glass'-published jointly with his physicist brother, now Brigadier C. L. Lindemann), astrophysies, and his well-known melt. ing-point formula. The last, which was the subject of his first independent paper, was characteristic: his simple physical model of a crystal lattice melting when its atoms oscillate so violently as to hit their neighbours enabled him to relate, with a minimum of calculation, the melting-point of a material to its Einstein single frequency.

Lindemann's strong loyalty to Britain cut short all this work in 1914, for it took him to the Royal Aircraft Establishment at Farnborough, where he was one of several outstanding physicists who devoted themselves to the many problems arising in the new field of aeronautics. Most of his work was concerned with the instruments of flight; but he is best known for his diagnosis of the way to recover an aireraft from the hitherto fatal condition of spinning. $\mathrm{He}$ had learnt to fly, and he undertook the trials himself : their success matched his courage, and Lindemann's technique became a standard drill. It has been said that he was not a good pilot, but it should be remembered that there was no obligation whatever for him to fly, and furthermore that he had only one good eye. He doubted the advantages of binocular vision, and would point out that he "had not done too badly" at tennis without it. Indeed, he had won several championships in Germany and 